\title{
Linagliptin use in older individuals with type 2 diabetes
}

This article was published in the following Dove Press journal:

Clinical Interventions in Aging

16 July 2014

Number of times this article has been viewed

\author{
Richard E Pratley ${ }^{1-3}$ \\ 'Florida Hospital Diabetes Institute, \\ ${ }^{2}$ Translational Research Institute for \\ Metabolism and Diabetes, ${ }^{3}$ Sanford- \\ Burnham Medical Research Institute, \\ Orlando, FL, USA
}

\begin{abstract}
Older people have the highest prevalence of type 2 diabetes mellitus (T2DM) of any age group and are thus frequent users of glucose-lowering agents. Because individuals 65 years or older are underrepresented in clinical studies, there is a lack of information regarding the efficacy and safety of available treatments in this population. Additionally, a high prevalence of comorbidities, polypharmacy, and frailty can make treatment of T2DM in this population challenging. Safety is an important consideration when choosing a treatment for older individuals. Renal impairment is quite common in older patients with T2DM and can contribute to hypoglycemia. Hypoglycemia can lead to serious consequences, such as falls and fractures, and cognitive changes. As such, hemoglobin $\mathrm{A}_{1 \mathrm{c}}$ treatment targets, typically $<7 \%$ in the general population, are less stringent in older people, with the goal being an individualized target that balances efficacy and safety. Many glucose-lowering agents can cause adverse events detrimental to older individuals, such as hypoglycemia (insulin, sulfonylureas), weight gain (sulfonylureas, thiazolidinediones), gastrointestinal events (metformin), and fractures (thiazolidinediones), and are contraindicated or require dose adjustments in those with renal impairment (most oral/injectable agents). Orally administered dipeptidyl peptidase (DPP)-4 inhibitors have a low risk of hypoglycemia and are generally well tolerated. Linagliptin is the only DPP-4 inhibitor excreted through nonrenal pathways and therefore does not require any dose adjustment in older patients with kidney disease. This paper reviews the findings of a recent study by Barnett et al assessing the efficacy and safety of the DPP-4 inhibitor linagliptin in patients with T2DM aged 70 years or older, which concluded that linagliptin may be a useful glucose-lowering option for older patients with T2DM.
\end{abstract}

Keywords: DPP-4 inhibitors, clinical trial, renal impairment, hypoglycemia

\section{Type 2 diabetes mellitus in older individuals}

Older individuals represent one of the fastest growing segments of the population. ${ }^{1}$ According to the US Centers for Disease Control and Prevention, 26.9\% of US residents aged 65 years and older had type 2 diabetes mellitus (T2DM) in 2010, and another $25 \%$ are at risk for developing the condition. ${ }^{2}$ About $40 \%$ of individuals with T2DM are above the age $65 .^{3}$ Despite the magnitude of the problem, very little evidence is available to guide treatment of T2DM in older individuals. ${ }^{4}$ Good trials to identify appropriate treatment targets for older individuals with T2DM are lacking. Additionally, very few prospective clinical studies have assessed the available therapies in the older individuals. A recent review indicated that $<1 \%$ of interventional trials target people above the age of $65,{ }^{5}$ resulting in a marked information gap and unmet need in this population.

Treatment of T2DM in older individuals is complex because of the clinical heterogeneity of the geriatric population. Other factors complicating treatment in older individuals include the high prevalence of comorbid conditions (eg, hypertension, 
cognitive impairment, etc), as well as a high prevalence of macrovascular and microvascular complications, such as cardiovascular disease and chronic kidney disease (CKD). Moreover, high rates of polypharmacy within this age group can increase the risk for developing adverse drug reactions.

Older individuals are especially prone to the adverse consequences of diabetes treatment, such as hypoglycemia, a major concern in this population because it can result in serious complications, including falls, fractures, cardiovascular events, and worsening cognitive function. Hypoglycemia is a leading cause of admissions to the hospital among patients over the age of 65 with drug-induced adverse events (AEs). ${ }^{4}$ Thus, when selecting an agent for the treatment of T2DM in older individuals, it is important to balance efficacy and safety by taking into account the unique characteristics of older patients, their comorbid conditions, and the potential AEs.

\section{Treatment paradigm for T2DM in older individuals}

Treatment targets in older adults should be adjusted depending on patients' functional status and life expectancy. For highly functioning older patients with minimal comorbidities and a long life expectancy, treatment targets are similar to the ones recommended for a younger population (ie, hemoglobin $\mathrm{A}_{1 \mathrm{c}}\left[\mathrm{HbA}_{1 \mathrm{c}}\right]<7 \%$ ). For those who have severe comorbidities, including coronary artery disease or cerebrovascular disease, who have poor general functioning and a limited life expectancy, less stringent treatment targets (ie, $\mathrm{HbA}_{1 \mathrm{c}} 7.5 \%-8.5 \%$ ) are recommended. ${ }^{4}$

For most individuals, metformin is the first-line therapy. Because of the high prevalence of CKD in older individuals, assessment of renal function is imperative before starting metformin therapy. When metformin alone is no longer adequate to provide glycemic control, the American Diabetes Association (ADA) Standards of Medical Care in Diabetes $^{6}$ recommend the addition of another agent, such as a sulfonylurea, thiazolidinedione (TZD), a dipeptidyl peptidase (DPP)-4 inhibitor, or a glucagon-like peptide (GLP)-1 receptor agonist.

When choosing a specific treatment for older individuals, either as mono- or combination therapy, health care practitioners need to consider the profile of the therapeutic agent. For example, sulfonylureas can cause hypoglycemia and weight gain, and are inappropriate for frail patients at risk for falls, fractures, cardiovascular disease (CVD) events, and cognitive impairment. The ADA consensus report Diabetes in Older Adults specifically states that glyburide use should be avoided in older individuals because of its long half-life and potential for precipitating hypoglycemia. ${ }^{4}$ TZDs, which are not associated with a high risk for hypoglycemia, can cause weight gain and edema, and have a propensity to cause heart failure in predisposed individuals. In addition, TZDs have been associated with an increased risk of long bone fractures and thus, may not be the optimal choice for older postmenopausal women.

Incretin-based therapies, such as GLP-1 receptor agonists and DPP-4 inhibitors, have characteristics that make them attractive for use in older individuals, such as a low propensity for hypoglycemia and drug-drug interactions. Although GLP-1 receptor agonists are effective in older individuals ${ }^{7,8}$ and are associated with a low risk of hypoglycemia, ${ }^{4}$ a paucity of data, especially prospective trials, addresses their use in the geriatric population. Moreover, GLP-1 receptor agonist use can be limited by the need for injection and the high prevalence of nausea, and may be undesirable in frail, older individuals because of their effect on appetite and the potential for weight loss. DPP-4 inhibitors, oral agents administered once daily, are a good option in older individuals, either as first-line therapy or in combination with other antidiabetic agents.

\section{DPP-4 inhibitors in older individuals}

Clinical trials of DPP-4 inhibitors show that these agents are efficacious and generally well tolerated. ${ }^{9}$ Because of their unique mechanism of action, DPP-4 inhibitors can be combined with other medications for the treatment of diabetes, including metformin, sulfonylureas, TZDs, and insulin therapy, and are thus generally useful in the treatment paradigm.

Features of this drug class that may benefit older patients include the low inherent risk of hypoglycemia and the lack of AEs, such as weight gain, fluid retention, and gastrointestinal symptoms. Furthermore, DPP-4 inhibitors have no apparent negative effects on bone. Another desirable aspect of the DPP-4 inhibitor class is the low risk of drug-drug interactions, which is particularly important in the older population, where polypharmacy is a concern.

However, the high prevalence of CKD in older patients can affect the clearance of certain DPP-4 inhibitors. Sitagliptin, ${ }^{10}$ alogliptin, ${ }^{11}$ saxagliptin, ${ }^{12}$ and vildagliptin ${ }^{13}$ require a dose adjustment in patients with CKD because they are cleared, at least in part, through the kidneys. Linagliptin, which is primarily excreted by the bile, does not require a dose adjustment in patients with $\mathrm{CKD}$, nor does it require dose adjustment in patients with hepatic impairment. ${ }^{14}$ 
A number of pooled analyses of Phase III and IV clinical trials have examined the efficacy and safety of DPP-4 inhibitors in the older population. Pooled analyses of vildagliptin, ${ }^{15,16}$ saxagliptin, ${ }^{17,18}$ and alogliptin ${ }^{19}$ data demonstrated that patients $\geq 65$ years of age achieved good glycemic control without increased risk of hypoglycemia or other AEs. A systematic review of DPP-4 inhibitor data in older patients concluded that these agents are as efficacious and well tolerated in older population as in younger people. ${ }^{20}$ Several prospective trials with DPP-4 inhibitors, including studies with vildagliptin, ${ }^{21}$ sitagliptin, ${ }^{22}$ and alogliptin ${ }^{23}$ have also demonstrated that this class of medications is safe and well tolerated in an older patient population with T2DM.

A recent study by Barnett et al examined the efficacy and tolerability of a newer DPP-4 inhibitor, linagliptin, in patients age 70 years or older with T2DM. ${ }^{24}$ In contrast to other prospective trials that assessed DPP-4 inhibitors as monotherapy, this study assessed linagliptin in older patients whose glycemia was not controlled by up to three other glucose-lowering drugs, including insulin. It therefore more closely resembled a real-world situation with respect to patients' age, polypharmacy burden, long-standing diabetes, and comorbidities.

\section{Summary of the linagliptin prospective clinical trial in older patients with T2DM Trial design}

The multinational, Phase III, clinical trial, Efficacy and Safety of Linagliptin in Elderly Patients With Type 2 Diabetes (NCT01084005), was conducted in five countries and 33 clinical sites. ${ }^{24}$ The entry criteria for the study included patient age $\geq 70$ years of age, with T2DM and an $\mathrm{HbA}_{1 \mathrm{c}}$ level $\geq 7 \%$. Patients could be on metformin, sulfonylureas, basal insulin, or a combination of treatments. Exclusion criteria included a fasting plasma glucose of $13.3 \mathrm{mmol} / \mathrm{L}$; hepatic dysfunction as indicated by liver function tests more than three times the upper limit of normal; myocardial infarction; stroke or transient ischemia within the previous 3 months; or treatment with other antidiabetic agents except those noted above. Patients were randomized in a 2:1 ratio to receive oncedaily linagliptin $5 \mathrm{mg}$ or placebo on top of their existing glucose-lowering regimen. Randomization was stratified by $\mathrm{HbA}_{1 \mathrm{c}}(<8.5 \%$ versus $[\mathrm{vs}] \geq 8.5 \%)$ and insulin use. The primary end point for this trial was change in $\mathrm{HbA}_{1 \mathrm{c}}$ from baseline to 24 weeks. The background diabetes treatments were maintained for 12 weeks, after which they could be adjusted. Rescue medication, in the case of hyperglycemia, could be added if patients exceeded certain criteria during randomized therapy (a confirmed fasting glucose level of $>13.3 \mathrm{mmol} / \mathrm{L}$ in weeks $1-12$ or $>11.1 \mathrm{mmol} / \mathrm{L}$ in weeks 13-24; or random glucose test $>22.2 \mathrm{mmol} / \mathrm{L}$, with two or more measurements on different days and one done after an overnight fast). Events suspected to be stroke or cardiac ischemia (including myocardial infarction) were reviewed by an independent clinical end point committee, which adjudicated the events.

\section{Patient characteristics}

Overall, the patients randomized to linagliptin $(n=162)$ and placebo $(n=79)$ had very similar baseline characteristics. The mean age of the population was 74.9 years (range $70-91$ years), with $44 \%$ aged $\geq 75$ years. Most patients were white (linagliptin 97\%, placebo 96\%) and predominantly male (linagliptin $72 \%$, placebo $62 \%$ ). The body mass index at baseline was $29.7 \mathrm{~kg} / \mathrm{m}^{2}$.

Baseline $\mathrm{HbA}_{1 \mathrm{c}}$ levels were $7.8 \%$ and $7.7 \%$ for the linagliptin and placebo groups, respectively, and a substantial percentage of patients had an $\mathrm{HbA}_{1 \mathrm{c}}$ level $\geq 8 \%$ (linagliptin, 36\%, placebo $26 \%$ ). Of note, more than half the patients (linagliptin 56\%, placebo 54\%) had a diabetes duration $>10$ years. Impairment in renal function was observed in close to $80 \%$ of patients; slightly more than half of patients had mild renal impairment with an estimated glomerular filtration rate (eGFR) between 60 and $90 \mathrm{~mL} / \mathrm{min} / 1.73 \mathrm{~m}^{2}$; one-quarter had moderate or more severe renal impairment. The majority of patients were taking metformin as background therapy (linagliptin $83 \%$, placebo $89 \%$ ), and a substantial number were also treated with a sulfonylurea (linagliptin 55\%, placebo 59\%). In general, they had multiple comorbidities with approximately two-thirds of patients taking five or more concomitant medications in addition to their diabetes treatment.

\section{Efficacy}

Of the 241 patients randomized, 220 (91\%) completed 24 weeks of treatment. The primary outcome of change in $\mathrm{HbA}_{1 \mathrm{c}}$ from baseline to week 24 was significantly in favor of linagliptin, which decreased $\mathrm{HbA}_{1 \mathrm{c}}$ by $-0.64 \%$ (Figure 1). $\mathrm{HbA}_{1 \mathrm{c}}$ declined rapidly with linagliptin treatment and reached a nadir by 12 weeks, remaining stable for the duration of the study. In addition, linagliptin resulted in significantly greater reductions in fasting plasma glucose levels $(-1.15 \mathrm{mmol} / \mathrm{L})$. There were no significant differences in the efficacy of linagliptin by subgroups of age, duration of diabetes, renal 


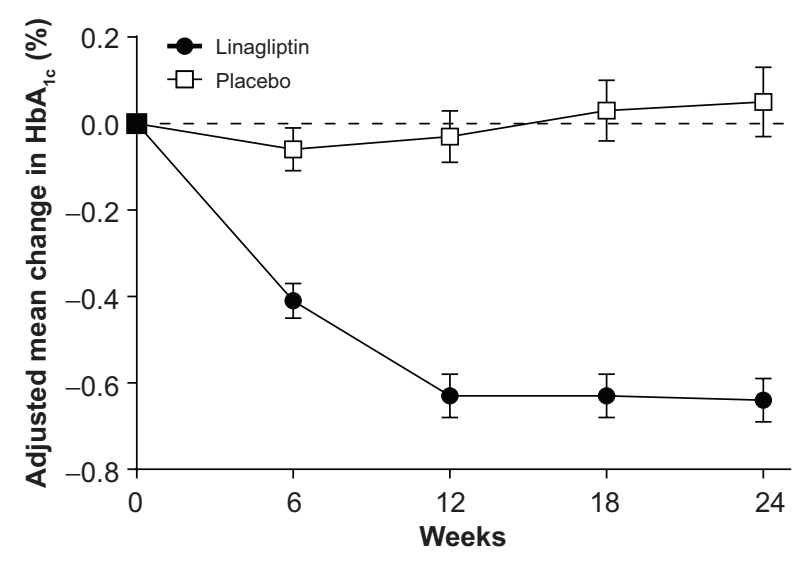

Figure I Change from baseline in $\mathrm{HbA}_{1 c}$ over 24 weeks in the full analysis set. Notes: Reprinted from the Lancet, 382(9902), Barnett AH, Huisman H, Jones R, von Eynatten M, Patel S, Woerle HJ, Linagliptin for patients aged 70 years or older with type 2 diabetes inadequately controlled with common antidiabetes treatments: a randomised, double-blind, placebo-controlled trial, 1413-1423, Copyright 2013, with permission from Elsevier. ${ }^{24}$ Adjusted mean change in $\mathrm{HbA}_{\mathrm{lc}}$. The error bars represent SE. The full analysis set consisted of all randomized patients who received at least one dose of study drug and who had a baseline and at least one on-treatment $\mathrm{HbA}_{\mathrm{lc}}$ measurement. Data are from a mixed model for repeated measurements, using observed cases with treatment, visit, previous use of insulin, and visit by treatment interactions as fixed classification effects and baseline $\mathrm{HbA}_{\mathrm{lc}}$ as a linear covariate.

Abbreviations: $\mathrm{HbA}_{I c}$, hemoglobin $\mathrm{A}_{\mathrm{Ic}}$; $\mathrm{SE}$, standard error of the mean.

function, or concomitant therapy. Of note, individuals with a long duration of diabetes ( $>10$ years), achieved reductions in $\mathrm{HbA}_{1 \mathrm{c}}$ similar to those with a shorter disease duration. Thus, these data indicate that linagliptin is efficacious in an older individuals population, with a decrease in $\mathrm{HbA}_{1 \mathrm{c}}$ similar to that observed in Phase III clinical trials with linagliptin and other DPP-4 inhibitors. ${ }^{9}$

Of those patients with a baseline $\mathrm{HbA}_{1 \mathrm{c}}$ level of $\geq 7 \%$, $38.9 \%$ in the linagliptin arm reached an $\mathrm{HbA}_{1 \mathrm{c}}<7 \%$ compared with $8.3 \%$ in the placebo arm. Similarly, $54.4 \%$ of linagliptin-treated patients had an $\mathrm{HbA}_{1 \mathrm{c}}$ reduction of $\geq 0.5 \%$ compared with $12.8 \%$ of placebo-treated patients. $\mathrm{HbA}_{1 \mathrm{c}}$ of $<7.5 \%,<8.0 \%$, or $<8.5 \%$ - in patients with baseline $\mathrm{HbA}_{1 \mathrm{c}}$ above those levels - was achieved by $49.5 \%, 63.8 \%$, and $71.4 \%$, of linagliptin patients, respectively and by $27.3 \%, 30.0 \%$, and $45.5 \%$ of placebo-treated patients, respectively.

These results are in line with current guidelines from the American Diabetes Association for older individuals, which recommend $\mathrm{HbA}_{1 \mathrm{c}}$ goals of $<7.5 \%$ for healthy patients with few chronic illnesses, $>8 \%$ for more complex patients with multiple chronic comorbidities and mild to moderate cognitive impairment, and $>8.5 \%$ for those in poor health. ${ }^{25}$

Rescue treatment was needed by fewer patients in the linagliptin group than in the placebo group (4.4\% [7/160] vs $14.1 \%[11 / 78])(P=0.0048)$.

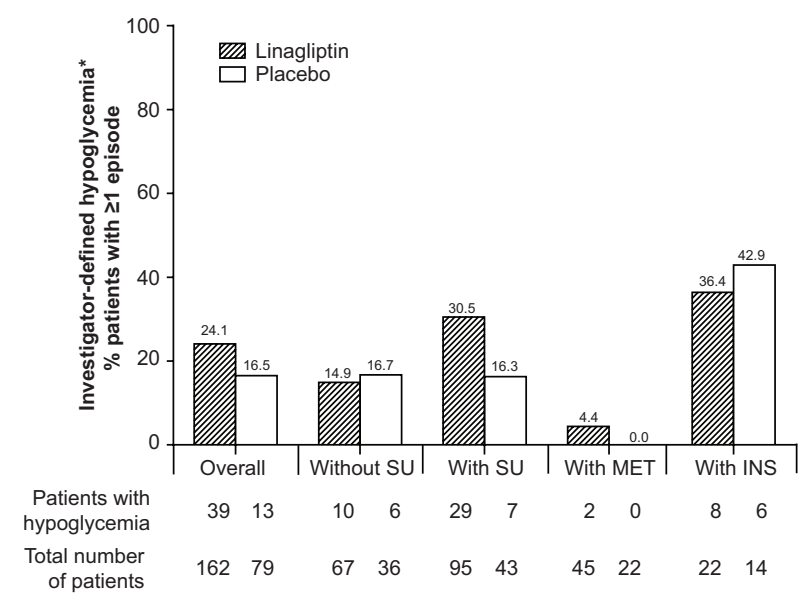

Figure 2 Hypoglycemia in the treated set of patients.

Notes: Reprinted from the Lancet, 382(9902), Barnett AH, Huisman H, Jones R, von Eynatten M, Patel S, Woerle HJ, Linagliptin for patients aged 70 years or older with type 2 diabetes inadequately controlled with common antidiabetes treatments: a randomised, double-blind, placebo-controlled trial, 1413-1423, Copyright 2013, with permission from Elsevier. ${ }^{24}$ The treated set consisted of all patients who received at least one dose of study drug. *Confirmed plasma glucose concentration of $3.9 \mathrm{mmol} / \mathrm{L}$ or less, or symptoms attributed to hypoglycemia, or both.

Abbreviations: INS, insulin (with or without metformin); MET, metformin only; $\mathrm{SU}$, sulfonylurea (with or without other antidiabetic drugs).

\section{Safety}

The proportion of patients reporting AEs was identical in linagliptin- and placebo-treated patients (76\%). Most of these events were mild or moderate in intensity. The most common AEs observed were hypoglycemia, nasopharyngitis, diarrhea, and hyperglycemia. No clinically relevant changes in body weight, heart rate, blood pressure, or renal function were reported with linagliptin treatment.

Hypoglycemia occurred in $24 \%$ of linagliptin-treated patients vs $16.5 \%$ of those receiving placebo (Figure 2). Most of the hypoglycemic episodes were mild to moderate in nature. One episode of severe hyperglycemia occurred in a patient receiving linagliptin who was also receiving metformin and sulfonylureas. On further analysis, it appears that most hypoglycemic episodes occurred in patients on linagliptin or placebo who were also treated with either sulfonylureas (linagliptin, $30.5 \%$ vs placebo, $16.3 \%$ ) or insulin (linagliptin, $36.4 \%$ vs placebo, $42.9 \%$ ). In patients not receiving sulfonylureas, the incidence of hypoglycemia was comparable between groups ( $14.9 \%$ in the linagliptin-treated group vs $16.7 \%$ in the placebo-treated group), despite the improvement in glycemic control. This finding reinforces the relatively low risk of hypoglycemia with linagliptin, alone or in combination with metformin.

Serious AEs occurred in 8.6\% $(n=14)$ and $6.3 \%(n=5)$ of patients treated with linagliptin and placebo, respectively, and no deaths were reported in this study. Very few drug-related 
AEs led to discontinuation (one patient in each group), and there were no cases of pancreatitis recorded.

\section{Summary}

This randomized, prospective, controlled trial revealed that linagliptin was efficacious and well tolerated in older patients with T2DM who had a high burden of comorbid conditions and who were on multiple concomitant medications. The efficacy of linagliptin was comparable to that observed in the general population with T2DM in Phase III clinical trials. Of note, linagliptin remained efficacious across the treatment spectrum, including in patients who had longstanding diabetes and those treated with insulin. This finding may reflect the multiple mechanisms of action of DPP-4 inhibitors with respect to glucose lowering, particularly their effects in suppressing inappropriate glucagon secretion. The limitations of this study include a short duration (24 weeks) and use of placebo rather than an active comparator.

This trial revealed a safety and tolerability profile that was very similar to that observed in other clinical trials with DPP-4 inhibitors. Linagliptin was well tolerated, with very few AEs attributable to drug therapy. Although hypoglycemic episodes were observed, these could almost entirely be explained by concomitant use of sulfonylureas. This trial also highlights that linagliptin was well tolerated in patients with CKD as the majority of patients in this trial had at least some degree of renal impairment. Linagliptin was efficacious in patients with CKD and did not require any dose adjustment this population.

The results of the present trial are generally consistent with results observed with other DPP-4 inhibitors, which indicates similar efficacy in older individuals and a generally good tolerability profile, albeit in a more vulnerable patient population that resembles more closely a real-world scenario. These data collectively reinforce the use of DPP-4 inhibitors as a useful treatment for diabetes in older individuals, particularly among those who have multiple comorbidities, who are on multiple medications, and who are at high risk for the complications of treatment, such as hypoglycemia.

\section{Disclosure}

Medical writing assistance was provided by Linda Merkel, PhD, of Envision Scientific Solutions. The author was fully responsible for all content and editorial decisions, was involved at all stages of manuscript development, and approved the final version of the review.

Medical writing assistance was supported financially by Boehringer Ingelheim. Boehringer Ingelheim was given the opportunity to check the data used in the manuscript (for factual accuracy only).
The author was a consultant for AstraZeneca/BMS, Eisai, Gilead, GlaxoSmithKline, ICON, Janssen, Lexicon, Ligand, Lilly, Mannkind, Merck, Novartis, Novo Nordisk, ONO, Profil, Roche, Sanofi Aventis, Takeda, and Zealand Pharma. The author received honoraria from Amylin, AstraZeneca/BMS, Eisai, Glaxo Smith Kline, Janssen, Lexicon, Mannkind, Merck, Novo Nordisk, Profil, Roche, Sanofi Aventis, Takeda, Zealand Pharma. The author also received research grants from Glaxo Smith Kline, Lily, Mannkind, Merck, Novartis, Novo Nordisk, Pfizer, Roche, Sanofi Aventis, and Takeda. Lastly, the author was the speaker for Merck and Novo Nordisk. All honoraria are directed toward a non-profit foundation supporting research and education.

\section{References}

1. US Bureau of the Census. 65+ in the United States. Washington, DC: US Government Printing Office; 1996.

2. Centers for Disease Control and Prevention. National Diabetes Fact Sheet. National Estimates and General Information on Diabetes and Prediabetes in the United States. Atlanta, GA: Centers for Disease Control and Prevention; 2011.

3. Pleis JR, Ward BW, Lucas JW. Summary health statistics for U.S. adults: National Health Interview Survey, 2009. Vital Health Stat 10. 2010(249):1-207.

4. Kirkman MS, Briscoe VJ, Clark N, et al. Diabetes in older adults Diabetes Care. 2012;35(12):2650-2664.

5. Lakey WC, Barnard K, Batch BC, Chiswell K, Tasneem A, Green JB. Are current clinical trials in diabetes addressing important issues in diabetes care? Diabetologia. 2013;56(6):1226-1235.

6. American Diabetes Association. Standards of medical care in diabetes - 2013. Diabetes Care. 2013;36 Suppl 1:S11-S66.

7. Bode BW, Brett J, Falahati A, Pratley RE. Comparison of the efficacy and tolerability profile of liraglutide, a once-daily human GLP-1 analog, in patients with type 2 diabetes $\geq 65$ and $<65$ years of age: a pooled analysis from phase III studies. Am J Geriatr Pharmacother. 2011;9(6):423-433.

8. Germino FW. Noninsulin treatment of type 2 diabetes mellitus in geriatric patients: a review. Clin Ther. 2011;33(12):1868-1882.

9. Monami M, Iacomelli I, Marchionni N, Mannucci E. Dipeptydil peptidase-4 inhibitors in type 2 diabetes: a meta-analysis of randomized clinical trials. Nutr Metab Cardiovasc Dis. 2010;20(4):224-235.

10. Januvia ${ }^{\circledR}$ (sitagliptin) tablets [prescribing information]. Whitehouse Station, NJ: Merck \& Co.; 2010 Inc.

11. Nesina ${ }^{\circledR}$ (alogliptin) tablets [prescribing information]. Deerfield, IL: Takeda Pharmaceuticals America, Inc.; 2013.

12. Onglyza ${ }^{\circledR}$ (saxagliptin) tablets [prescribing information]. Princeton, NJ: Bristol-Myers Squibb Co; 2013.

13. Galvus ${ }^{\circledR}$ (vildagliptin) tablets [prescribing information]. Basel: Novartis International AG; 2013.

14. Tradjenta ${ }^{\circledR}$ (linagliptin) tablets [prescribing Information]. Ingelheim: Boehringer-Ingelheim Int GmbH; 2013.

15. Pratley RE, Rosenstock J, Pi-Sunyer FX, et al. Management of type 2 diabetes in treatment-naive elderly patients: benefits and risks of vildagliptin monotherapy. Diabetes Care. 2007;30(12):3017-3022.

16. Schweizer A, Dejager S, Bosi E. Comparison of vildagliptin and metformin monotherapy in elderly patients with type 2 diabetes: a 24-week, double-blind, randomized trial. Diabetes Obes Metab. 2009;11(8):804-812.

17. Doucet J, Chacra A, Maheux P, Lu J, Harris S, Rosenstock J. Efficacy and safety of saxagliptin in older patients with type 2 diabetes mellitus. Curr Med Res Opin. 2011;27(4):863-869. 
18. Karyekar CS, Ravichandran S, Allen E, Fleming D, Frederich R. Tolerability and efficacy of glycemic control with saxagliptin in older patients (aged $\geq 65$ years) with inadequately controlled type 2 diabetes mellitus. Clin Interv Aging. 2013;8:419-430.

19. Pratley RE, McCall T, Fleck PR, Wilson CA, Mekki Q. Alogliptin use in elderly people: a pooled analysis from phase 2 and 3 studies. $J \mathrm{Am}$ Geriatr Soc. 2009;57(11):2011-2019.

20. Schwartz SL. Treatment of elderly patients with type 2 diabetes mellitus: a systematic review of the benefits and risks of dipeptidyl peptidase-4 inhibitors. Am J Geriatr Pharmacother. 2010;8(5): $405-418$.

21. Strain WD, Lukashevich V, Kothny W, Hoellinger MJ, Paldánius PM. Individualised treatment targets for elderly patients with type 2 diabetes using vildagliptin add-on or lone therapy (INTERVAL): a 24 week, randomised, double-blind, placebo-controlled study. Lancet. 2013; 382(9890):409-416.
22. Barzilai N, Guo H, Mahoney EM, et al. Efficacy and tolerability of sitagliptin monotherapy in elderly patients with type 2 diabetes: a randomized, double-blind, placebo-controlled trial. Curr Med Res Opin. 2011;27(5):1049-1058.

23. Rosenstock J, Wilson C, Fleck P. Alogliptin versus glipizide monotherapy in elderly type 2 diabetes mellitus patients with mild hyperglycaemia: a prospective, double-blind, randomized, 1-year study. Diabetes Obes Metab. 2013;15(10):906-914.

24. Barnett AH, Huisman H, Jones R, von Eynatten M, Patel S, Woerle HJ. Linagliptin for patients aged 70 years or older with type 2 diabetes inadequately controlled with common antidiabetes treatments: a randomised, double-blind, placebo-controlled trial. Lancet. 2013; 382(9902):1413-1423.

25. Sue Kirkman M, Briscoe VJ, Clark N, et al; Consensus Development Conference on Diabetes and Older Adults. Diabetes in older adults: a consensus report. J Am Geriatr Soc. 2012;60(12):2342-2356.
Clinical Interventions in Aging

\section{Publish your work in this journal}

Clinical Interventions in Aging is an international, peer-reviewed journal focusing on evidence-based reports on the value or lack thereof of treatments intended to prevent or delay the onset of maladaptive correlates of aging in human beings. This journal is indexed on PubMed Central, MedLine,

\section{Dovepress}

CAS, Scopus and the Elsevier Bibliographic databases. The manuscript management system is completely online and includes a very quick and fair peer-review system, which is all easy to use. Visit http://www.dovepress. com/testimonials.php to read real quotes from published authors. 